\title{
Medical Image Segmentation using Genetic Algorithm
}

\author{
Divya Kaushik \\ Computer Science Department \\ IMS Engineering College \\ Ghaziabad,U.P., India
}

\author{
Utkarsha Singh \\ Computer Science Department \\ IMS Engineering College \\ Ghaziabad,U.P., India \\ Vijai Singh \\ Computer Science Department \\ IMS Engineering College \\ Ghaziabad,U.P., India
}

\author{
Paridhi Singhal \\ Computer Science Department \\ IMS Engineering College \\ Ghaziabad,U.P., India
}

\begin{abstract}
Segmentation is used as the first and the most important phase in the recognition and treatment of a disease in analyzing medical images like MRI images. It is challenging due to poor contrast and artifacts that result in missing or diffuse organ/tissue boundaries. In this paper, we will discuss different ways to automate the segmentation of medical images. We except further improvements can be achieved by incorporating as much prior information as possible (e.g. texture, shape, \& spatial location of organs) into a single framework.
\end{abstract}

\section{General Terms}

Digital Image Processing, Medical Image Segmentation, Genetic Algorithm.

\section{Keywors}

Medical image segmentation, Genetic algorithm, Clustering.

\section{INTRODUCTION}

Image data plays a vital role in medical informatics. They help in extracting meaningful information such as volume, shape, motion of organs, to detect abnormalities.

Thus segmentation is vital in the analysis of medical images which can be useful in many applications such as distinguishing the arteries borders from each other in angiography, the size of tumor and its response to treatment, interpretation of operation, the study of brain growth and recognition of tumor and so on [1]. Therefore, it is obvious that segmentation is often used as the first and most important phase in the recognition and treatment of a disease in analyzing medical images.

Now for the above mentioned optimization problem Genetic algorithms are one of the most powerful techniques in a large solution space. They are used where exhaustive search for solution is expensive in terms of computation time.

\subsection{Image Segmentation Techniques}

\subsubsection{Edge Detection Technique}

Edge detection is a type of image segmentation techniques which determines the presence of an edge or line in an image and outlines them in an appropriate way [27]. The main purpose of edge detection is to simplify the image data in order to minimize the amount of data to be processed [6]. Generally, an edge is defined as the boundary pixels that connect two separate regions with changing image amplitude attributes such as different constant luminance and tristimulus values in an image [27][18][28]. The detection operation begins with the examination of the local discontinuity at each pixel element in an image. Amplitude, orientation, and location of a particular subarea in the image that is of interest are essentially important characteristics of possible edges [27]. Based on these characteristics, the detector has to decide whether each of the examined pixels is an edge or not.

Frei and Chen [27] suggested that edge detection is best carried out by simple edge detector, monitored by a morphological thinning and linking process to optimize the boundaries. They used the three most frequent edge detection methods which are, Roberts Edge Detection, Sobel Edge Detection and Prewitt edge detection. Also, they gave an overview of first and second order derivative edge detections, edge fitting detection model as well as the detector performance evaluation [14].

In the recent research, it was proposed that we can detect the edges of an image without determining the threshold value with the implementation of fuzzy logic based algorithm. The suggested methodology begins by scanning the images via floating $3 \times 3$ pixel window. Fuzzy inference system has 8 inputs, which resembles to 8 pixels of prompt scanning matrix; one of the outputs tells that whether the pixel under observation is "black", "white" or "edge" pixel. Rule base embraces of sixteen rules, which classify the target pixel [23]. The projected way results for different taken images which are compared to those obtained with the linear Sobel operator.

\subsubsection{Thresholding Technique}

Thresholding is one of the easiest methods of image segmentation. Thresholding can be used to create binary images from a gray scale images. Threshold segmentation techniques can be divided in three diverse groups:

a. Local techniques are based on the native characteristics of the pixels and their neighborhoods.

b. Global techniques segment an image on the base of data obtain globally (e.g. by using image histogram; global texture properties).

c. Merge, split and growing practices use both the notions of homogeneity and geometrical vicinity in order to attain good segmentation results. Finally 
image segmentation, is used to group pixels into regions to determine an image's composition [5][8].

Fuzzy C-means, its improvement methods algorithm and strategies for remote sensing image segmentation can offer less iterations times to converge to global optimal solution. At the same time, it has good stability and robustness. Its good effect of segmentation can improve accuracy and efficiency of remote sensing image threshold segmentation [3].

Color images can also be thresholded. One approach is to designate a separate threshold for each of the RGB components of the image and then combine them with an AND operation [14]. This reflects the way the camera works and how the data is stored in the computer, but it does not correspond to the way that people recognize color. Therefore, the HSL and HSV color models are more often used. It is also possible to use the CMYK color model (Pham et al., 2007).

\subsubsection{Region Growing Based Technique}

Region growing technique involves selecting initial seed points and adding neighboring pixels to the region depending on the appropriate membership criteria such as color similarity. In the initial stage seed regions are recognized based on calculation of variance of Red, Green and Blue components and choosing the first seed point having the minimum R, G, B variance product. Four connected neighbors are used to grow from the seed point. This process repeats itself until no change is found in two consecutive stages [26].

The major shortcoming of this algorithm is that it segments the image based only on color/intensity, therefore it gives poor results for textured image [26]. Also, it depends largely on the value of $\mathrm{T}$ in likelihood term computation which takes different values for different images.

Region Growing can also be implemented by Mean or MaxMin strategies [20]. Firstly, the image is partitioned into uniform blocks for processing. Region growing is then performed by examining properties of each block and merging them with adjacent blocks which satisfy some criteria. Region growing is implemented by examining properties of each block and merging them with adjacent blocks that satisfy some criteria. Alternatively, the mean values of the blocks can be used to determine which blocks should be merged.

The two algorithms [20] founded hitches in dealing with various image features. In comparison to the mean algorithm the max-min algorithm did a better job of preserving edges and handling some textures. On the contrary the mean algorithm did better on images with speckle. Ultimately the choice of the algorithm really depends on the image you are dealing with. Neither of these algorithms does any sort of high level spatial correlation. At the end it is understandable that they fail for images which contain complex regions.

\subsubsection{Clustering Technique}

Clustering is an unsupervised learning task, in this we need to identify a finite set of classes known as clusters to classify each pixel [12]. Clustering make use of no training stages instead train themselves using accessible data. It is mainly used when classes are recognized in advance. A similarity measures is defined between pixels [6], and then similar pixels on grouping together form clusters. The grouping of pixels into clusters is based on the principle of maximizing the intra class similarity and maximizing the inter class similarity. The quality of a clustering result depends on both the similarity measure used by the method and its implementation. Clustering algorithms are classified as hard clustering, k- means clustering, fuzzy clustering, etc.

\subsubsection{Histogram based Segmentation}

The main supposition of this approach is that the objects within each class should have high degree of similarity, whereas those in different classes are supposed to be dissimilar [7]. The clusters are originated by mode analysis of the multidimensional histogram of the considered vectors through a non-iterative peak-climbing approach. The histogram holds a uniform color transition that facilitates us to do a window-based smoothing during retrieval.

\subsubsection{Graph Partitioning Method}

Spectral graph partitioning [11] provides a dominant approach in the field of image segmentation. One of the methods to find partitions is with a small isoperimetric constant, demanding solution to a linear system instead of an eigenvector problem. It produces the high quality segmentations of spectral methods, but with improved speed and stability.

\subsubsection{Hybrid Image Segmentation Using \\ Watershed \& Fast Region Merging}

One of the segmentation problem is how to segment an image into homogeneous segments such that after combining two neighbors we get a heterogeneous segment. Histogram technique represents the simple probability distribution function of intensity values of any image. Edge based technique uses differential filter in order of image gradient or Laplacian and then grouped them into contours and represents the surface. Region based segmentation technique segments the image into a set of homogeneous regions then merges them according to certain decision rules [10]. In the Markov random field based segmentation technique the true image is realized by a Markov or Gibbs random field with a distribution function. Hybrid image segmentation is a combination of edge based and region based techniques. In this image is firstly partitioned into regions and then merged using split and merge technique and after that it detects the contours using edge-based technique. 
Table 1.Comparison of Image Segmentation Techniques [16]

\begin{tabular}{|c|c|c|c|}
\hline $\begin{array}{c}\text { Segmentation } \\
\text { Techniques }\end{array}$ & Method Description & Advantages & Disadvantages \\
\hline $\begin{array}{c}\text { Thresholding } \\
\text { method }\end{array}$ & $\begin{array}{l}\text { Requires that the histogram of } \\
\text { an image has a no. of peaks, } \\
\text { each corresponds to a region. }\end{array}$ & $\begin{array}{l}\text { 1)It does not need prior } \\
\text { information of the image. } \\
\text { 2) For a wide class of } \\
\text { images satisfying the } \\
\text { requirement, this method } \\
\text { works very well with low } \\
\text { computation complexity. }\end{array}$ & $\begin{array}{l}\text { 1) Does not work well for an image } \\
\text { without any obvious peaks or with } \\
\text { broad and flat } \\
\text { Valleys. } \\
\text { 2) Does not consider the spatial } \\
\text { details, so cannot guarantee that the } \\
\text { segmented regions are contiguous. }\end{array}$ \\
\hline $\begin{array}{l}\text { Clustering } \\
\text { Approach }\end{array}$ & $\begin{array}{l}\text { Assumes that each region in } \\
\text { the image forms a separate } \\
\text { cluster in the feature space. } \\
\text { Can be generally broken into } \\
\text { two steps: } \\
\text { 1) Categorize the points in the } \\
\text { feature space into clusters; } \\
\text { 2) Map the clusters back to } \\
\text { the spatial domain to form } \\
\text { separate regions. }\end{array}$ & $\begin{array}{l}\text { Straight forward for } \\
\text { classification and easy for } \\
\text { implementation. }\end{array}$ & $\begin{array}{l}\text { 1) How to determine the no. of } \\
\text { clusters (known as cluster validity). } \\
\text { 2) Features are often image dependent } \\
\text { \& how to select features so as to } \\
\text { obtain satisfactory segmentation } \\
\text { results remains unclear. } \\
\text { 3) Does not utilize spatial information. }\end{array}$ \\
\hline $\begin{array}{c}\text { Region Based } \\
\text { Approaches }\end{array}$ & $\begin{array}{lrr}\text { Group pixels } & \begin{array}{r}\text { into } \\
\text { homogeneous }\end{array} \\
\text { regions. } \\
\text { Including region } & \text { growing, } \\
\text { region splitting, } & \text { region } \\
\text { merging or their combination. }\end{array}$ & $\begin{array}{l}\text { Work best when the region } \\
\text { homogeneity criterion is } \\
\text { easy to define. They are } \\
\text { also more noise immune } \\
\text { than edge detection } \\
\text { approach. }\end{array}$ & $\begin{array}{l}\text { 1) Are by nature sequential \& quite } \\
\text { expensive both in computational time } \\
\text { and memory. } \\
\text { (2) Region growing has inherent } \\
\text { dependence on the selection of seed } \\
\text { region and the order in which pixels } \\
\text { and regions are examined. } \\
\text { 3) The resulting segments by region } \\
\text { splitting appear too square due to the } \\
\text { splitting scheme. }\end{array}$ \\
\hline $\begin{array}{c}\text { Edge Detection } \\
\text { Approach }\end{array}$ & $\begin{array}{l}\text { Based on the detection of } \\
\text { discontinuity, normally tries } \\
\text { to locate points with more or } \\
\text { less abrupt changes in gray } \\
\text { level. } \\
\text { Usually classified into two } \\
\text { categories: } \\
\text { sequential\& parallel. }\end{array}$ & $\begin{array}{l}\text { Edge detecting technique is } \\
\text { the way in which human } \\
\text { perceives objects \& works } \\
\text { well for images having } \\
\text { good contrast between } \\
\text { regions. }\end{array}$ & $\begin{array}{l}\text { 1) Does not work well with images in } \\
\text { which the edges are ill-defined or } \\
\text { there are too many edges. } \\
\text { 2) It is not a trivial job to produce a } \\
\text { closed curve or boundary. } \\
\text { 3) Less immune to noise than other } \\
\text { techniques, e.g., Thresholding and } \\
\text { clustering. }\end{array}$ \\
\hline
\end{tabular}

\subsection{Medical Image Segmentation}

Segmentation is applied in medical images when the brightness of the images becomes weaker so that making different in recognizing the tissues borders. Thus, the exact segmentation of medical images is an essential process in recognizing and curing an illness. Thus, it is obvious that the purpose of clustering in medical images is the recognition of damaged areas in tissues. Different techniques have been introduced for clustering in different fields such as engineering, medicine, data mining and so on. Medical image analysis is prominently used by physicians and doctors to investigate and diagnose of structure and function of the body [1].

\subsection{Genetic Algorithm}

Genetic algorithms are based on natural selection discovered by Charles Darwin [22]. They employ natural selection of fittest individuals as optimization problem solver. Optimization is performed through natural exchange of genetic material between parents. Offspring's are formed from parent genes. Fitness of offspring's is evaluated [21] [4]. The fittest individuals are allowed to breed only. In computer world, genetic material is replaced by strings of bits and natural selection replaced by fitness function. Matting of parents is represented by cross-over and mutation operations.

A simple GA (Figure 1) consists of five steps [4]

1. Start with a randomly generated population of $\mathrm{N}$ chromosomes, where $\mathrm{N}$ is the size of population, 1 length of chromosome $\mathrm{x}$. 
2. Calculate the fitness value of function $\varphi(x)$ of each chromosome $\mathrm{x}$ in the population.

3. Repeat until N offspring's are created:

a. Probabilistically select a pair of chromosomes from current population using value of fitness function.

b. Produce an offspring yi using crossover and mutation operators, where $\mathrm{i}=1,2 \ldots \mathrm{N}$.

4. Replace current population with newly created one.

5. Go to step 2 .

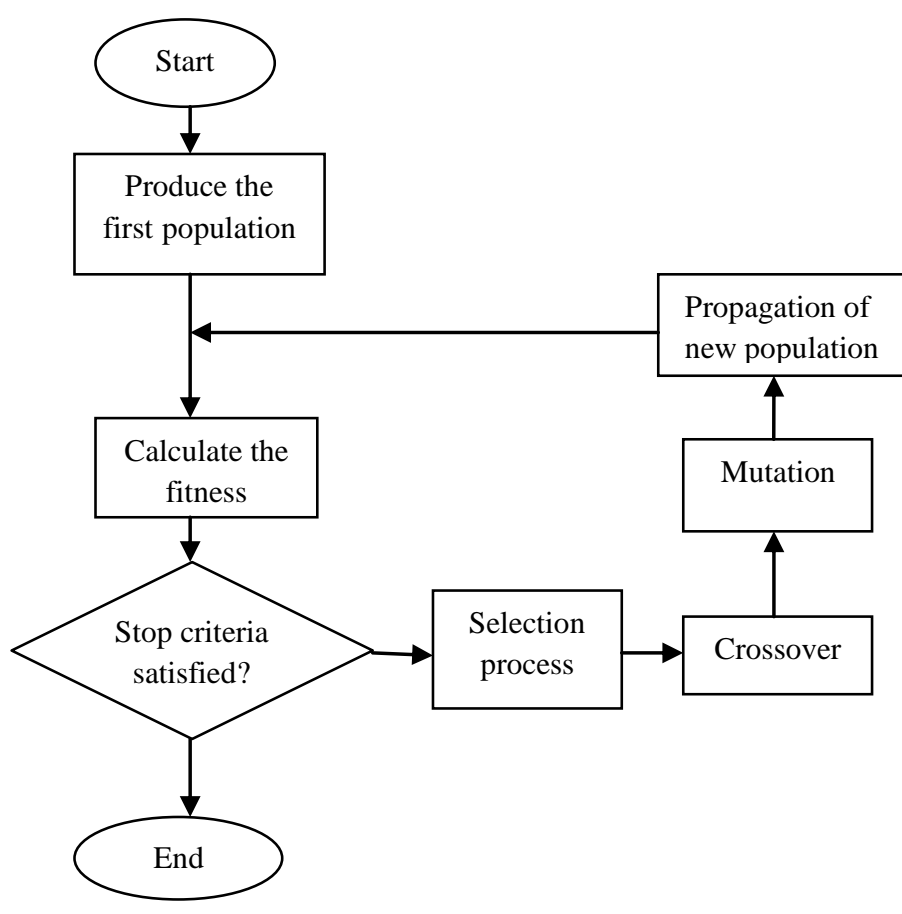

Fig 1: Flowchart for Genetic Algorithm

\section{LITERATURE RIVIEW}

UjjwalMaulik proposed Texture based technique in genetic algorithm for finding real textures and image classification. He used GA-based optimization algorithm to produce a population of individual sub-images that are tested via a quantitative objective function, ranked using a linear fitness and decrement scheme, and modified using crossover [25].

AkabarShahrzadKhashandarag, MirkamalMirnia and AidinSakhavati proposed a new method combining genetic algorithm and K-Means algorithm for clustering medical images. In this combined technique, variable string length genetic algorithm (VGA) is used for the determination of the optimal cluster centres [1].

P. Kanungo, P.K. Nanda and U.C. Samal presented a new approach based on GeneticAlgorithm (GA) for selection of threshold from the histogram of images. Specifically GA based crowding algorithm is proposed for determination of the peaks and valleys of the histogram. They provided experimental results for histogram with bimodal feature, however, this technique can be extended to multi-threshold selection for histograms with multimodal feature [17].

BaladhandapaniArunadevi and Subramaniam N. Deepa explored Extreme Learning Machine Classifier algorithm for implementing genetic algorithm. This method is modeled for automatic brain tissue and pathological tumor classification and segmentation of 3D MRI tumor images [2].

PayelGhosh and Melanie Mitchell proposed a genetic algorithm for automating the segmentation of the prostate on two-dimensional slices of pelvic computed tomography (CT) images. In this approach they represented segmenting curve using a level set function, which is evolved using a genetic algorithm (GA) [15].

R. Ganesan and S. Radhakrishnan proposed a novel method for automatic segmentation of Computed Tomography (CT) brain images. Their method consists of two major phases. In the 1st phase, the original images are enhanced by using Selective Median Filter (SMF) and in the 2nd phase the GA is used to segment the image. They applied their proposed method to real patient CT images [24].

Tianzi Jiang, Faguo Yang, Yong Fan, and David J. Evans proposed a parallel genetic algorithm for cell image segmentation under severe noise. A priori knowledge about cell shape is incorporated in their method. The segmentation results of noisy human thyroid and small intestine cell images demonstrate that the proposed method is very successful in segmenting images of elliptically shaped cells [17].

S. Cagnoni, A. B. Dobrzeniecki, R. Poli and J. C. Yanch have described a method for evolving adaptive procedures for contour-based segmentation of anatomical structures in 3D medical data sets. Here the segmentation is driven by the contour-tracking strategy that relies on an elastic-contour model whose parameters are also optimized by the GA [21]. 
Table 2.Comparison of Various Algorithms

\begin{tabular}{|c|c|c|c|c|c|c|c|c|c|}
\hline Approach & Selection & $\begin{array}{c}\text { Crossove } \\
\text { r }\end{array}$ & $\begin{array}{c}\text { Mutatio } \\
\mathbf{n}\end{array}$ & $\begin{array}{l}\text { Fitness } \\
\text { Criteria }\end{array}$ & $\begin{array}{c}\text { Populatio } \\
\text { n size }\end{array}$ & $\begin{array}{l}\text { Stopping } \\
\text { criteria }\end{array}$ & Coding & Feature & $\begin{array}{c}\text { Future } \\
\text { work }\end{array}$ \\
\hline $\begin{array}{c}\text { [1]Textur } \\
\text { e Based } \\
\text { Techniqu } \\
\text { e[25] }\end{array}$ & $\begin{array}{l}\text { Roulette } \\
\text { Wheel } \\
\text { Parent } \\
\text { Selection }\end{array}$ & $\mathrm{P}_{\mathrm{c}}=0.8$ & $\begin{array}{c}P_{m}=0.00 \\
5\end{array}$ & $\begin{array}{l}\text { Linear } \\
\text { fitness } \\
\text { function }\end{array}$ & $\mathrm{N}_{\text {size }=100}$ & $\begin{array}{l}\text { Until all the } \\
\text { pixels of } \\
\text { input image } \\
\text { have been } \\
\text { scanned }\end{array}$ & $\begin{array}{l}\text { Decremen } \\
\mathrm{t} \text { function } \\
\text { with a } 9 * 9 \\
\text { median } \\
\text { filter }\end{array}$ & $\begin{array}{l}\text { Uses GA for } \\
\text { real texture } \\
\text { and image } \\
\text { classification }\end{array}$ & $\begin{array}{c}\text { Can be } \\
\text { extended to } \\
2 \text { GA based } \\
\text { pattern } \\
\text { detection } \\
\text { techniques: } \\
\text { Structured } \\
\text { texture, } \\
\text { Random } \\
\text { noise }\end{array}$ \\
\hline $\begin{array}{c}\text { [2]GA } \\
\text { with } \\
\text { Variable } \\
\text { String } \\
\text { Length } \\
\text { Chromos } \\
\text { ome } \\
{[1]}\end{array}$ & $\begin{array}{c}\text { Low Fitness } \\
\text { Function } \\
\text { Selection }\end{array}$ & $P_{c}=0.2$ & $P_{m}=0.2$ & $\begin{array}{l}\text { Minimu } \\
\text { m } \\
\text { Distribu } \\
\text { tion } \\
\text { Clusteri } \\
\text { ng }\end{array}$ & $\mathrm{N}_{\text {size }}=30$ & $\begin{array}{c}\text { Until a } \\
\text { greater } \\
\text { value of } \\
\text { Dunn Index } \\
\text { has been } \\
\text { reached }\end{array}$ & $\begin{array}{c}\text { Chromoso } \\
\text { me length } \\
1_{\mathrm{i}}=2 * \mathrm{k}_{\mathrm{i}} \\
\left(\mathrm{k}_{\mathrm{i}}: \text { no. of }\right. \\
\text { clusters })\end{array}$ & $\begin{array}{c}\operatorname{Max}^{\mathrm{m}} \text { no. of } \\
\text { chromosomes } \\
\left(\mathrm{k}_{\max }\right)= \\
\left(\operatorname{rand}() \% \mathrm{k}^{*}\right)+ \\
2\end{array}$ & \\
\hline $\begin{array}{c}\text { [3] GA } \\
\text { with } \\
\text { Threshol } \\
\text { d[17] }\end{array}$ & $\begin{array}{c}\text { Tournament } \\
\text { strategy }\end{array}$ & $\mathrm{P}_{\mathrm{c}}=0.9$ & $\begin{array}{c}\mathrm{P}_{\mathrm{m}}=0.05 \\
\text { (follows } \\
\text { decayin } \\
\mathrm{g} \\
\text { exponen } \\
\text { tial } \\
\text { function } \\
\text { ) }\end{array}$ & $\begin{array}{l}\text { Normali } \\
\text { zed } \\
\text { histogra } \\
\mathrm{m} \\
\text { function }\end{array}$ & $\begin{array}{c}\mathrm{N}_{\text {size }}=20 \\
\text { (between } \\
\text { two } \\
\text { correspond } \\
\text { ing gray } \\
\text { values) }\end{array}$ & $\begin{array}{c}\text { Until } \\
\text { elements of } \\
\text { respective } \\
\text { classes are } \\
\text { equally fit }\end{array}$ & $\begin{array}{c}\text { RGB } \\
\text { componen } \\
\text { ts }\end{array}$ & $\begin{array}{c}\text { Peaks at grey } \\
\text { value }=91,148 \\
\text { Threshold= } \\
117\end{array}$ & $\begin{array}{c}\text { To address } \\
\text { two class } \\
\text { images with } \\
\text { noises and } \\
\text { images } \\
\text { requiring } \\
\text { multiple } \\
\text { thresholds. }\end{array}$ \\
\hline $\begin{array}{c}\text { [4]GA } \\
\text { using } \\
\text { Extreme } \\
\text { Machine } \\
\text { Learning } \\
\text { Classifier } \\
\text { Algorith } \\
\text { m } \\
{[2]}\end{array}$ & & $\mathrm{P}_{\mathrm{c}}=0.1$ & $\mathrm{P}_{\mathrm{m}}=0.02$ & $\begin{array}{c}\text { Classifie } \\
\text { r using } \\
\text { ELM \& } \\
\text { IPSO } \\
\text { techniqu } \\
\text { e }\end{array}$ & $\mathrm{N}_{\text {size }}=50$ & & $\begin{array}{c}\text { Uses Grey } \\
\text { Level } \\
\text { Occurrenc } \\
\text { e Matrix } \\
\text { (GLCM) } \\
\text { \& Run } \\
\text { Length } \\
\text { Matrix } \\
\text { (RLM) }\end{array}$ & $\begin{array}{c}\text { Characterizes } \\
\text { brain tissue as } \\
\text { Grey Matter } \\
\text { (GM) \& } \\
\text { White Matter } \\
\text { (WM) }\end{array}$ & $\begin{array}{c}\text { Can be } \\
\text { extended on } \\
\text { T2, Flair \& } \\
\text { PD images } \\
\text { to construct } \\
\text { fully } \\
\text { automatic } \\
\text { MRI } \\
\text { analyzer }\end{array}$ \\
\hline $\begin{array}{c}\text { [5]GA } \\
\text { using } \\
\text { Edge \& } \\
\text { Feature } \\
\text { Detection } \\
{[15]}\end{array}$ & $\begin{array}{c}\text { Rank } \\
\text { Selection }\end{array}$ & $\begin{array}{l}\mathrm{P}_{\mathrm{c}}=1.0 \\
\text { (Single } \\
\text { Point) }\end{array}$ & $\begin{array}{l}\mathrm{P}_{\mathrm{m}}=0.02 \\
\text { per gene }\end{array}$ & $\begin{array}{c}\text { Fisher } \\
\text { Linear } \\
\text { Discrimi } \\
\text { nant } \\
\text { function }\end{array}$ & $\mathrm{N}_{\text {size }}=25$ & & & $\begin{array}{l}\text { Feature of a } \\
\text { given shape is } \\
\text { determined by } \\
\text { a match } \\
\text { between the } \\
\text { texture of its } \\
\text { enclosed } \\
\text { region \& } \\
\text { mean texture }\end{array}$ & $\begin{array}{c}\text { Can be } \\
\text { extended to } \\
\text { 3D }\end{array}$ \\
\hline $\begin{array}{c}\text { [6]Paralle } \\
\text { l GA } \\
{[24]}\end{array}$ & $\begin{array}{c}\text { Fitness } \\
\text { Proportional } \\
\text { model }\end{array}$ & $P_{c}=0.6$ & $P_{m}=0.1$ & $\begin{array}{l}\text { Distribu } \\
\text { tion } \\
\text { function }\end{array}$ & $\mathrm{N}_{\text {size }}=100$ & $\mathrm{~N}_{\text {pop }}=250$ & $\begin{array}{c}\text { Integer } \\
\text { (Chromos } \\
\text { ome } \\
\text { length =5) }\end{array}$ & $\begin{array}{c}\text { Incorporates } \\
\text { migration } \\
\text { operation }\end{array}$ & $\begin{array}{c}\text { To solve the } \\
\text { occlusion } \\
\text { problem } \\
\text { completely }\end{array}$ \\
\hline $\begin{array}{c}\text { [7]GA } \\
\text { using } \\
\text { Selective } \\
\text { Median } \\
\text { Filter } \\
\text { (SMF) } \\
\text { [19] }\end{array}$ & $\begin{array}{l}\text { Roulette } \\
\text { Wheel } \\
\text { Selection }\end{array}$ & $P_{c}=0.6$ & $\mathrm{P}_{\mathrm{m}}=0.03$ & $\begin{array}{c}\text { Local } \\
\text { fitness } \\
\text { value } \\
\text { compare } \\
\text { d with } \\
\text { Global } \\
\text { optimu } \\
\text { m value } \\
\end{array}$ & $\mathrm{N}_{\text {size }}=10$ & $\mathrm{No}_{\text {iter }}=100$ & & $\begin{array}{c}\text { Performance } \\
\text { is evaluated } \\
\text { using } \\
\text { Receiver } \\
\text { Operating } \\
\text { Characteristic } \\
\text { (ROC) curve } \\
\text { analysis }\end{array}$ & \\
\hline $\begin{array}{c}\text { [8]GA } \\
\text { (for } \\
\text { Adaptive } \\
\text { image } \\
\text { segmenta } \\
\text { tion) }[21]\end{array}$ & $\begin{array}{l}\text { Threshold- } \\
\text { crossing } \\
\text { selection } \\
\text { criteria }\end{array}$ & $\begin{array}{c}\mathrm{P}_{\mathrm{c}}=0.6 \\
\text { One point } \\
\text { crossover }\end{array}$ & $\begin{array}{c}P_{m}=0.00 \\
1\end{array}$ & $\begin{array}{l}\text { Fitness } \\
\text { value } \\
\text { ranging } \\
\text { around } \\
500-570\end{array}$ & $\mathrm{~N}_{\text {size }}=200$ & $\mathrm{~N}_{\text {pop }}=200$ & $\begin{array}{c}\text { Computer } \\
\text { assisted } \\
\text { segmentat } \\
\text { ion }\end{array}$ & $\begin{array}{c}\text { GA } \\
\text { repeatedly } \\
\text { converges to } \\
\text { almost same } \\
\text { fitness values }\end{array}$ & $\begin{array}{c}\text { To let GA } \\
\text { itself } \\
\text { dynamically } \\
\text { select } \\
\text { segmentatio } \\
\mathrm{n} \text { algorithm }\end{array}$ \\
\hline
\end{tabular}




\section{CONCLUSION}

In this paper, the brief idea of various segmentation methodologies applied for digital image processing has been explained. The study also reviews the research on various methodologies applied for medical image segmentation and the issues encountered in this field of study. This study can be considered as a simple guidance to the researcher for those who want to carry out their research study in the medical image segmentation.

Relevance of these approaches is the direct medical application for segmentation and edge detection. We have studied several digital image processing methods and discussed its parameters and future work.

Image segmentation has a promising future as the universal segmentation algorithm. However, in spite of several decades of research, there is no universally accepted method for image segmentation, as the result of image segmentation is affected by lots of factors, such as: spatial characteristics of the image continuity, homogeneity of images, texture, image content. Thus there is no single method which can be considered good for neither all type of images nor all methods equally good for a particular type of image. Due to all above factors, image segmentation remains a challenging problem in image processing and computer vision and is still a pending problem in the world.

\section{ACKNOWLEDGMENTS}

We express our heartfelt thanks to our guide and mentor (Vijai Singh), who has steered us to propose an innovative and fast algorithm for segmentation of medical images using genetic algorithm. We are highly obliged to him. We also express our gratitude towards all the others who have contributed to completion of this paper.

\section{REFERENCES}

[1] Akbar ShahrzadKhashandarag, MirkamalMirnia, AidinSakhavati, "A New Method for Medical Image Clustering Using Genetic Algorithm", IJCSI International Journal of Computer Science Issues, Vol. 10, Issue 1, No 1, January 2013.

[2] BaladhandapaniArunadevi, Subramaniam N. Deepa. "Brain Tumor Tissue Categorization In 3D Magnetic Resonance Images Using Improved PSO For Extreme Learning Machine”, Progress In Electromagnetics Research B, Vol. 49, 31-54, 2013.

[3] Du Gen-yuan, Miao Fang, Tian Sheng-li, Guo Xi-rong, "Remote Sensing Image Sequence Segmentation Based on the Modified Fuzzy C-means", Journal of Software, Vol. 5, No. 1, PP.28-35, 2009.

[4] Falkenauer, E., "Genetic Algorithms and Grouping Problems”, John Wiley \& Sons, Boston, 1998.

[5] Gonzalez and Woods, "Digital image processing", 2nd Edition, prentice hall, 2002.

[6] J. Canny, "A computational approach to edge detection," IEEE Trans. Pattern Analysis and Machine Intelligence, Vol. 8, No. 6, pp. 679-698, Nov. 1986.

[7] Jun Zhang, Kitakyushu Jinglu Hu, "Computer Science and Software Engineering", International Conference, 2008.

[8] Kenneth R. Castelman, "Digital image processing", Tsinghua Univ Press, 2003.

[9] Keri Woods, "Genetic Algorithms: Colour Image Segmentation Literature Review", July 24, 2007.
[10] K. K. Singh, A. Singh,"A Study of Image Segmentation Algorithms for Different Types of Images", International Journal of Computer Science Issues, Vol. 7, Issue 5, 2010.

[11] L. Grady, EL Schwartz, "Pattern Analysis and Machine Intelligence", IEEE Transactions, 2005

[12] M.E. Farmer and D. Shugars. "Application of genetic algorithms for wrapper-based im- age segmentation and classification", In IEEE Congress on Evolutionary Computation, pages 1300-1307, July 2006.

[13] M. Mitchell, "An introduction to genetic algorithms", The MIT Press, 1996, 208.

[14] N. Senthilkumaran, R. Rajesh, "Edge Detection Techniques for Image Segmentation - A Survey", Proceedings of the International Conference on Managing Next Generation Software Applications (MNGSA-08), 2008, pp.749-760.

[15] PayelGhosh, Melanie Mitchell, "Segmentation of Medical Images Usinga Genetic Algorithm".

[16] Prof. Dinesh D. Patil, Ms. Sonal G. Deore, "Medical Image Segmentation: A Review", IJCSMC, Vol. 2, Issue 1, January 2013, pg.22 - 27.

[17] P. Kanungo, P. K. Nanda, U. C. Samal, "Image Segmentation Using Thresholding and Genetic Algorithm", Volume 1, 2006.

[18] R. C. Gonzalez and R. E. Woods, Digital Image Processing. Upper Saddle River, NJ: Prentice-Hall, 2001 , pp. 572-585.

[19] R. Ganesan, S. Radhakrishnan, "Segmentation Of Computed Tomography Brain Images Using Genetic Algorithm", IJCS, 157-161, 2009.

[20] Shilpa Kamdi1, R.K.Krishna2. 1,2-Rajiv Gandhi College of Engineering, Research and Technology, "Image Segmentation and Region Growing Algorithm", Feb 1, 2012.

[21] S. Cagnoni, A. B. Dobrzeniecki, R. Poli, J. C. Yanch, "Genetic algorithm-based interactive segmentation of 3D medical images", 1999.

[22] S.E. Papadakis, P. Tzionas, V.G. Kaburlasos, J.B. Theocharis, "A genetic based approach to the type I structure identification". Informatica, 2005, Vol.16, No. $3,365-382$.

[23] Suryakant, NeetuKushwaha. "Edge Detection using Fuzzy Logic in Matlab," ISSN: 2277 128X, Volume 2, Issue 4, April, 2012.

[24] Tianzi Jiang, Faguo Yang, Yong Fan, David J. Evans. “A Parallel Genetic Algorithm for Cell Image Segmentation", August 2001.

[25] UjjwalMaulik, "Medical Image Segmentation Using Genetic Algorithms" IEEE Transaction On Information Technology In Biomedicine, VOL. 13, NO. 2, March 2009.

[26] Utkarsh Kumar Shah and Prof. A. Mukherjee, "BTP REPORT Image segmentation by region growing", April $15,2010$.

[27] W. Frei, C. Chen, "Fast Boundary Detection: A Generalization and New Algorithm," IEEE Trans. Computers, vol. C-26, no. 10, pp. 988-998, Oct. 1977.

[28] W. K. Pratt, "Digital Image Processing”. New York, NY: Wiley-Interscience, 1991, pp. 491-556. 